\title{
Kualitas Air Embung untuk Irigasi di Margodadi, Lampung Selatan
}

\author{
Tastaptyani Kurnia Nufutomo ${ }^{1}$, Firdha Cahya Alam ${ }^{2}$, Ayudia Hardiyani Kiranaratri ${ }^{3}$ \\ ${ }^{1,2}$ Program Studi Teknik Lingkungan, Jurusan Teknologi Infrastruktur dan Kewilayahan, ITERA \\ ${ }^{3}$ Program Studi Teknik Sipil, Jurusan Teknologi dan Kewilayahan, ITERA \\ Surel: 1'tastaptyani@gmail.com, ${ }^{2}$ alamfirdhacahya@gmail.com, ${ }^{3}$ ayu setioko@ gmail.com
}

\section{ABSTRAK}

Lampung Selatan saat ini sedang menghadapi krisis air. Hal ini disebabkan maraknya perubahan penggunaan lahan menjadi pembangunan infrastruktur yang menyebabkan penurunan cadangan air tanah dan juga masalah banjir. Pemerintah daerah saat ini mulai membangun reservoir sebagai fasilitas penyimpanan air. Embung adalah teknologi konservasi di lokasi tadah hujan untuk mengatasi ketersediaan air. Embung Margodadi di Lampung Selatan dibangun untuk menyimpan air hujan, mempertahankan ketersediaan air tanah dan juga membantu siklus hidrologi. Selain itu peruntukan air embungnya untuk irigasi perkebunan warga. Banyaknya manfaat dan potensi embung, sehingga penelitian awal perlu dilakukan dalam analisis kualitas air. Untuk menganalisis kualitas air menggunakan indeks kualitas air berdasarkan parameter yang ditentukan, termasuk DO, BOD, total padatan, Nitrat, Fosfat, kekeruhan, pH, suhu, dan fecal coliform. Hasil yang didapat dari analisis kualitas air dengan indeks, air embung masih layak digunakan untuk kebutuhan masyarakat, karena hasilnya masih mengikuti standar kualitas kelas 3, yaitu untuk irigasi.

\section{Kata kunci}

Embung, Kualitas Air, Irigasi,

Margodadi, Lampung Selatan.

\section{PENDAHULUAN}

Embung Margodadi dibangun oleh PUPR tahun 2003, dengan data teknis embungnya yaitu debit rencana banjir 9,05 $\mathrm{m} 3 /$ det, tinggi $6 \mathrm{~m}$, panjang $95,10 \mathrm{~m}$, lebar 5 $\mathrm{m}$, Volume embung $89,250 \mathrm{~m}^{3}$ dan elevasi puncak embung 99,6 MSL. Kondisi umum lokasi sampling dapat dilihat dari rona lingkungan disekitar embung, terdapat lahan perkebunan warga berupa kebun jagung, singkong, dan tanaman palawija lainnya, serta terdapat perumahan warga. Embung Margodadi saat ini dijadikan sebagai tempat tadah air hujan dan juga sebagai sumber air untuk mengairi perkebunan warga. Sumber air Embung Margodadi selain dari air hujan juga berasal dari aliran sungai Way SeputihSekampung. Terdapat vegetasi di permukaan air yang menutupi daerah pinggiran embung di bagian outlet.

Beberapa parameter fisika dan kimia serta biologi dari sampel air embung diukur dan dibandingkan dengan baku mutu kualitas air kelas 3 pada PP No. 82/2001. Hal ini dilakukan untuk mengetahui apakah nilai dari hasil pengukuran tersebut telah melewati nilai baku mutu atau masih dalam kriteria baku mutu yang baik. Sampel diambil pada tiga titik yaitu di inlet, tengah dan outlet. Parameter yang diukur diantaranya adalah $\mathrm{pH}$, suhu, DO, BOD, Nitrat, total fosfat, Kekeruhan, total solid, dan bakteri fecal 
coliform. Tujuan penelitian ini adalah untuk mengetahui kelayakan kualitas air dan status mutu air Embung Margodadi sesuai dengan kriteria kualitas air kelas 3 sebagai air untuk irigasi dengan menggunakan indeks kualitas air.

\section{METODE PENELITIAN}

Pengambilan sampel air embung ditentukan berdasarkan kedalaman, karena terdapat perbedaan temperature pada kedalaman 1 meter dibawah permukaan. Perbedaan temperature terjadi jika kedalaman kurang dari 10 meter. Namun Embung Margodadi kedalamannya kurang dari 10 meter, oleh karena itu tidak terdapat perbedaan temperature yang nyata.

Pengambilan sampel air dilakukan berdasarkan SNI 06-2412-1991, yaitu diambil dari tempat masuknya aliran air sungai yang masuk ke embung, bagian tengah dan tempat keluarnya air dari embung. Hal ini dapat dilihat pada Gambar 1, Stasiun 1 (air masuk), Stasiun 2 (air terjadi pencampuran), Stasiun 3 (air keluar). Pengambilan sampel air dengan cara grab sampel.

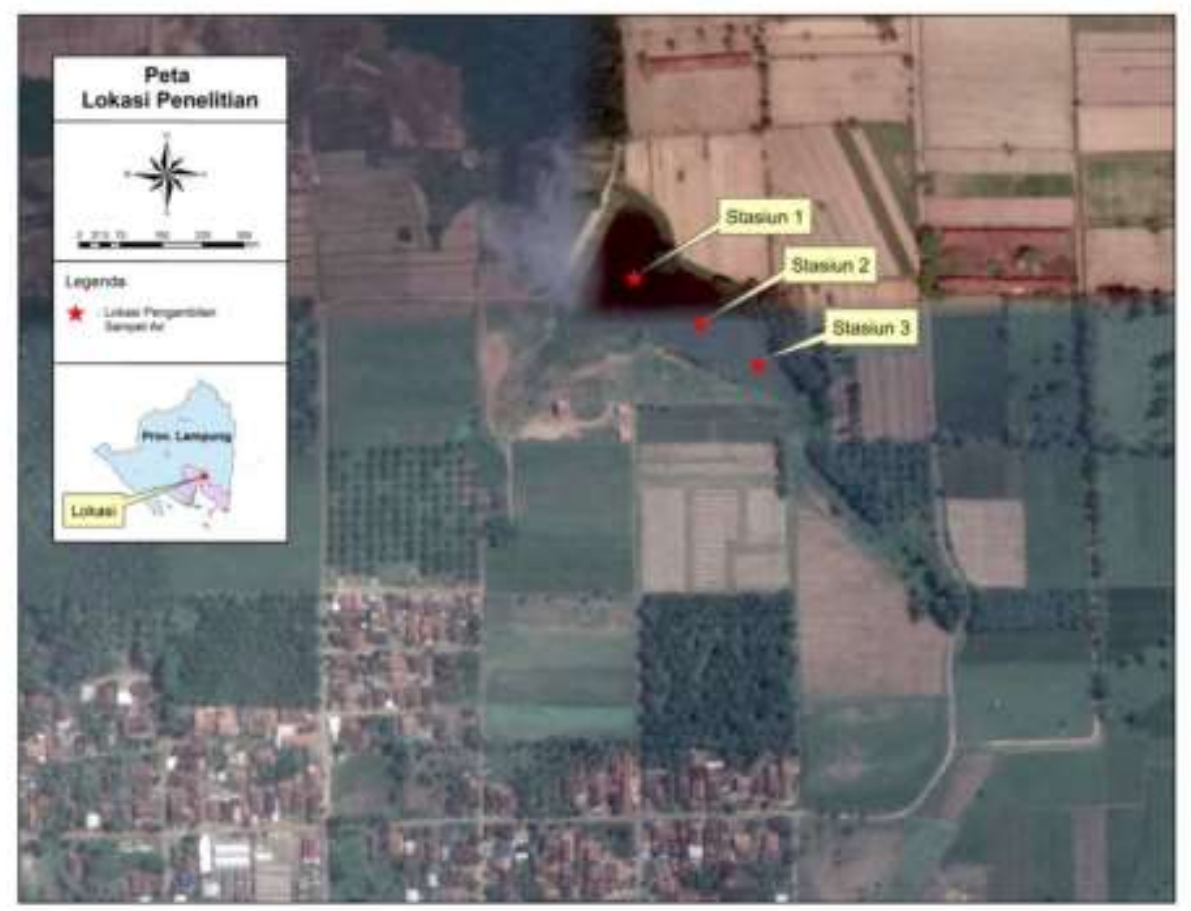

Gambar 1. Lokasi penelitian dan pengambilan sampel air

Pengukuran sampel air diukur dengan cara in situ dan ex situ. Pengukuran yang in situ yaitu $\mathrm{pH}$ dan suhu menggunakan alat portabel. Sedangkan ex situ yaitu BOD, DO, Total solid, Kekeruhan, nitrat, fosfat, dan bakteri fecal coliform. Analisis kualitas air dengan menggunakan indeks kualitas air NSF-WQI dilihat dari bobot masing-masing parameter. Bobot ini tertera di Tabel 1. Selanjutnya bobot (Wi) dari masing-masing parameter dikalikan dengan nilai yang diperoleh dari kurva sub index (Li). Untuk mendapatkan nilai kurva sub indeks dapat digunakan dengan calculator NSF-WQi secara online.
Tabel 1. Nilai bobot parameter indeks kualitas air

\begin{tabular}{|c|c|c|}
\hline No & Parameter & Weight Score \\
\hline 1 & $\mathrm{DO}$ & 0.17 \\
\hline 2 & $\mathrm{pH}$ & 0.11 \\
\hline 3 & BOD & 0.11 \\
\hline 4 & Temperature & 0.10 \\
\hline 5 & Total phosphate & 0.10 \\
\hline 6 & Nitrate & 0.10 \\
\hline 7 & Turbidity & 0.08 \\
\hline 8 & Total Solids & 0.07 \\
\hline \multirow[t]{2}{*}{9} & Fecal coliform & 0.16 \\
\hline & Total & 1 \\
\hline
\end{tabular}

Sumber: http://www.water-research.net/ 
Setelah menghitung semua parameternya lalu dijumlahkan dengan formula berikut ini:

(NSFWQI): $\sum_{\mathrm{i}=0}^{\mathrm{n}} \mathrm{W}_{\mathrm{i}} \mathrm{X} \mathrm{L} \mathrm{L}_{\mathrm{i}}$

Keterangan:

NSF WQI : Indeks kualitas air,

Wi : Bobot

$\mathrm{Li} \quad$ : Nilai dari kurva sub-indeks

Setelah didapatkan hasil perhitungan, maka dikategorikan hasilnya berdasarkan kriteria indeks kualitas air di Tabel 2. Parameter kualitas air dilakukan analisis di laboratorium Kimia Insitut Teknologi Sumatera dan juga Laboratorium UPT BPLHD Provinsi Lampung. Hasil analisis kualitas air tiap parameter dari tiap titik dapat terlihat dengan perbandingan dari grafik.

Tabel 2. Kriteria indeks kualitas air NSFWQI

\begin{tabular}{ll}
\hline NSF WQI Score & Criteria \\
\hline $0-25$ & Very Bad \\
$26-50$ & Bad \\
$51-70$ & Medium \\
$71-90$ & Good \\
$91-100$ & Excellent \\
\hline Sumber:http://www.water-research.net/
\end{tabular}

\section{HASIL DAN PEMBAHASAN}

\section{Parameter Fisik, Kimia dan Biologi}

\section{1. $\mathbf{p H}$}

Pada Gambar 2 terdapat perbedaan yang tidak jauh berbeda dari hasil pengukuran $\mathrm{pH}$ di tiap titik sampel. Pada titik I (inlet) dan titik II (tengah) hasil nilai ukur $\mathrm{pH}$ adalah 7,02, sedangkan di titik III (outlet) nilai $\mathrm{pH}$ nya 6.8. Nilai $\mathrm{pH}$ di 3 titik sampling tersebut masih diambang baku mutu dalam PP No.82 Tahun 2001 yaitu rentang $\mathrm{pH}$ 6-9.

Nilai pH pada Embung Margodadi masih dapat mendukung kehidupan organisme akuatik untuk dapat hidup di perairan tersebut. Jika nilai $\mathrm{pH}$ tidak sesuai dengan nilai baku mutu maka dapat bersifat toksik pada organisme akuatik. Nilai $\mathrm{pH}$ di perairan dipengaruhi oleh beberapa faktor, diantaranya adalah suhu, fotosintesis, respirasi, DO, dan keberadaan ion-ion dalam perairan tersebut ${ }^{[1]}$.

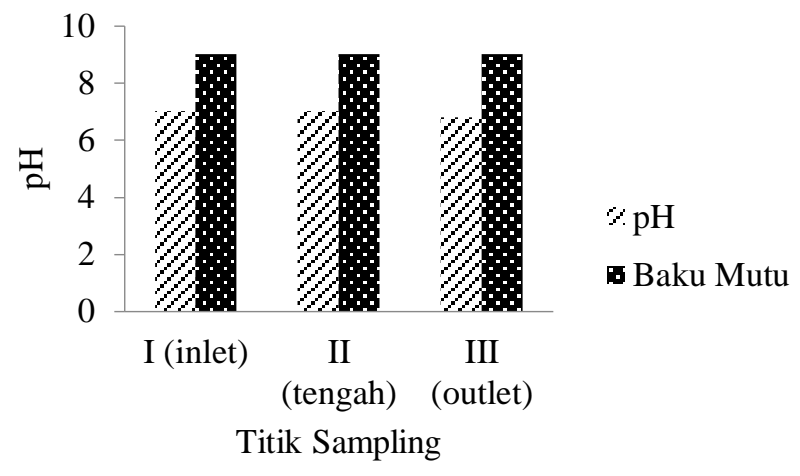

Gambar 2. pH pada Embung Margodadi dari setiap titik sampling

\section{Suhu}

Pada Gambar 3 tidak terdapat perbedaan suhu yang signifikan antar titik sampling. Pada titik I (inlet) suhunya yaitu $30,5^{\circ} \mathrm{C}$, titik II (tengah) yaitu $31^{\circ} \mathrm{C}$ dan titik III yaitu $31,5^{\circ} \mathrm{C}$. Pada PP No.82/2001 untuk baku mutu suhu yaitu deviasi 3 .

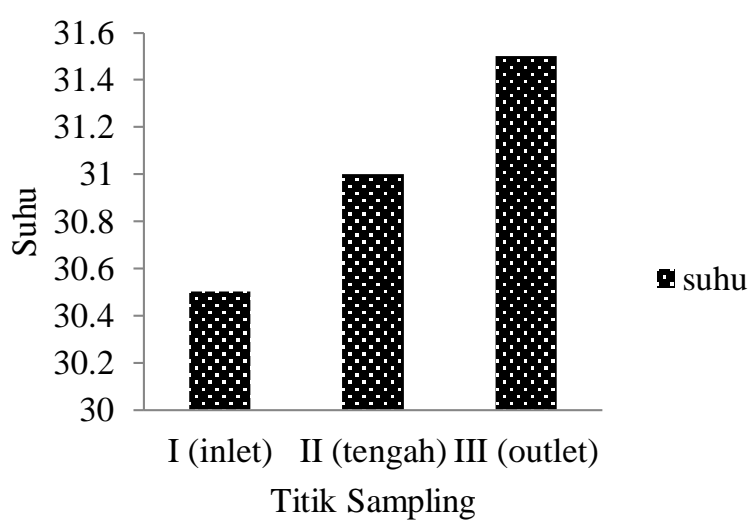

Gambar 3. Suhu pada Embung Margodadi di tiap titik sampling.

Nilai suhu pada Embung margodadi masih dalam keadaan aman untuk kehidupan organisme akuatik. Kisaran suhu bagi kehidupan organisme di perairan berdasarkan nilai baku mutu yaitu $18^{\circ} \mathrm{C}-30^{\circ} \mathrm{C}$.

\section{Total Solid (TS)}

Pada Gambar 4 terlihat perbedaan yang signifikan pada kondisi total solid di tiap titik sampling Embung Margodadi. 
Nilai TS pada titik I (inlet) yaitu 200 $\mathrm{mg} / \mathrm{L}$, titik II (tengah) yaitu $110 \mathrm{mg} / \mathrm{L}$ dan titik III (outlet) yaitu $410 \mathrm{mg} / \mathrm{L}$. Nilai TS di titik III sudah melewati nilai baku mutu kualitas air kelas 3 yaitu 400 $\mathrm{mg} / \mathrm{L}$.

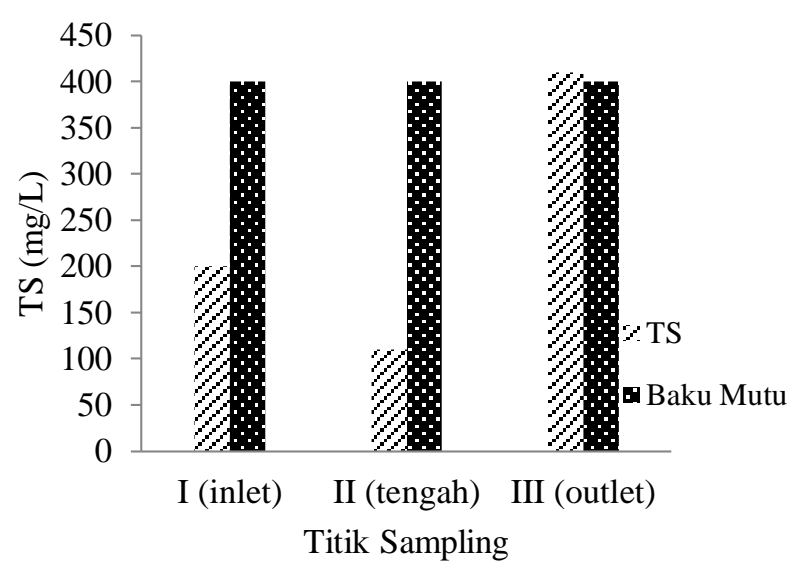

Gambar 4. Total solid pada Embung Margodadi di tiap titik sampling

Nilai TS tertinggi terdapat di titik III yaitu outlet. TS merupakan jumlah dari nilai TSS dan juga TDS. Dari hasil pengukuran TSS di outlet sangat tinggi. Tinginya nilai TSS dapat disebabkan karena pengaruh dari keceparan arus di setiap titik sampling. Jika kecepatan arus air lambat, maka dapat menyebabkan akumulasi materi-materi padatan yang tersuspensi bertambah. Selain itu tingginya TS juga dapat diakibatkan oleh adanya air limpasan dan juga aktifitas warga disekitar embung tersebut seperti memandikan sapi di pinggir embung atau membersihkan gerobak dan kendaraan mereka setelah berkebun.

\section{Kekeruhan}

Pada Gambar 5 kekeruhan pada embung margodadi terlihat perbedaan yang signifikan. Nilai kekeruhan pada titik I (inlet) dan titik II (tengah) yaitu 2,6 NTU, sedangkan di titik III (outlet) yaitu 2,8 NTU.

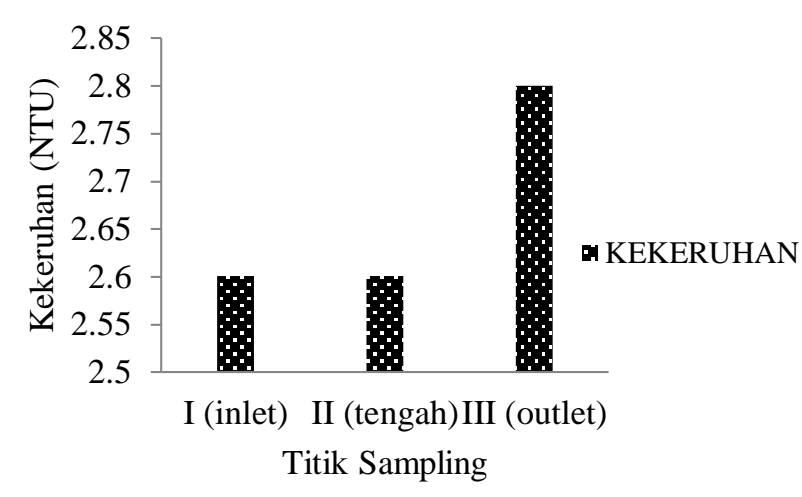

Gambar 5. Kekeruhan pada Embung Margodadi di tiap titik sampling

Nilai kekeruhan dipengaruhi oleh curah hujan yang tinggi, dimana saat hujan air limpasan akan masuk ke dalam badan air. Selain itu faktor lain seperti ukuran, bentuk dan warna serta tingkat pemantulan dari suatu particular juga mempengaruhi tingginya kekeruhan di badan air ${ }^{[2]}$.

\section{Dissolved Oxygen (DO)}

Pada Gambar 6 nilai DO pada tiap 3 titik sampling nya memiliki nilai yang sama yaitu $3 \mathrm{mg} / \mathrm{L}$. Nilai ini masih di dalam ambang batas baku mutu kualitas air pada PP 82/2001 yaitu $3 \mathrm{mg} / \mathrm{L}$.

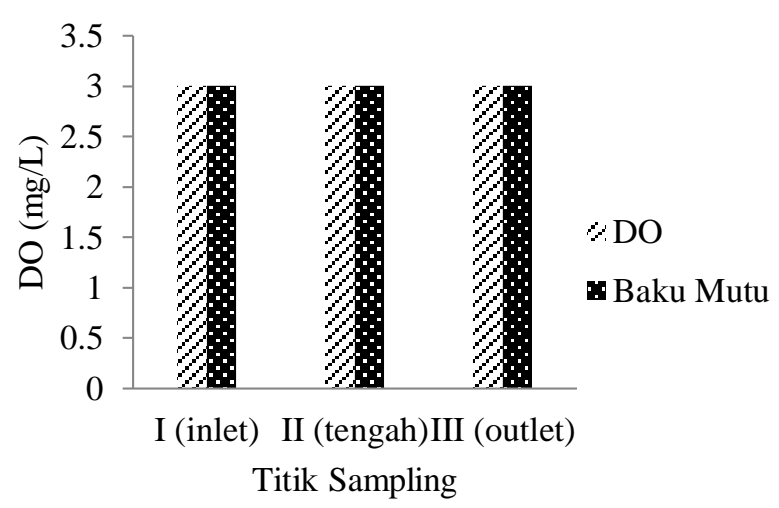

Gambar 6. DO pada Embung Margodadi di tiap titik sampling

Kelarutan oksigen bertambah seiring dengan penurunan temperature perairan, walaupun hubungan ini tidak berjalan secara linear ${ }^{[3]}$. 


\section{Biochemical Oxygen Demand (BOD)}

Pada Gambar 7 nilai BOD di titik I (inlet) yaitu $5 \mathrm{mg} / \mathrm{l}$, titik II (tengah) 4 $\mathrm{mg} / \mathrm{l}$ dan titik 3 (outlet) yaitu $6 \mathrm{mg} / \mathrm{l}$. nilai BOD pada tiap titik masih di ambang batas baku mutu kualitas air kelas 3. BOD menunjukkan jumlah oksigen yang dikonsumsi oleh proses resirasi mikroba aerob. Semakin tinggi BOD, maka semakin tinggi pencemaran yang terjadi di perairan.

\section{Nitrat}

Pada Gambar 8 nilai nitrat pada titik I dan II adalah $0, .3 \mathrm{mg} / \mathrm{l}$ sedangkan di titik III yaitu $1 \mathrm{mg} / \mathrm{l}$. Nilai nitrat masih dibawah nilai baku mutu kualitas air kelas 3 yaitu $20 \mathrm{mg} / \mathrm{l}$.

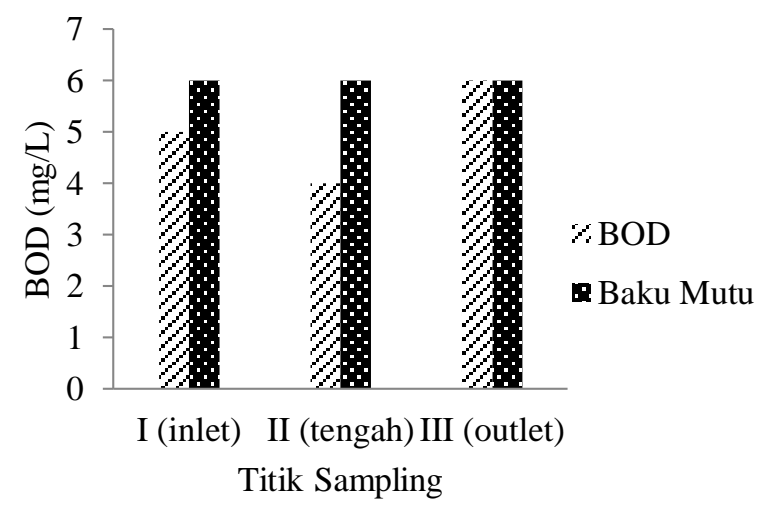

Gambar 7. BOD pada Embung Margodadi di tiap titik sampling

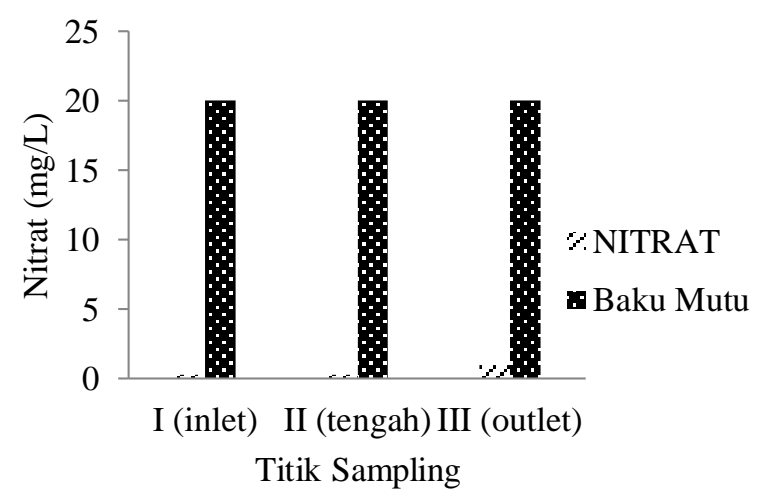

Gambar 8. Nitrat pada Embung Margodadi di tiap titik sampling

Nilai nitrat dipengaruhi oleh limbah pertanian, dan pemukiman. Tingginya nitrat dapat mengakibatkan terjadinya eutrofikasi perairan yang selanjutnya dapat menstimulir pertumbuhan algae dan tumbuhan air secara pesat (blooming $)^{[4]}$. Nilai nitrat dibagian outlet Embung Margodadi sudah menstimulus pertumbuhan tanaman di permukaan air namun belum terjadi blooming.

\section{Fosfat}

Pada Gambar 9 nilai fosfat pada titik I dan II adalah $1 \mathrm{mg} / \mathrm{l}$ sedangkan di titik III yaitu $0, .1 \mathrm{mg} / \mathrm{l}$. Nilai fosfat pada Embung Margodadi masih dalam ambang batas baku mutu kualitas air kelas 3 yaitu $1 \mathrm{mg} / \mathrm{l}$.

Peningkatan fosfat di perairan dapat menyebabkan timbulnya proses eutrofikasi di suatu ekosistem perairan yang menyebabkan terjadinya penurunan kadar oksigen terlarut, diikuti dengan timbulnya kondisi anaerob yang menghasilkan berbagai senyawa toksik, seperti methan, nitrit dan belerang ${ }^{[5]}$.

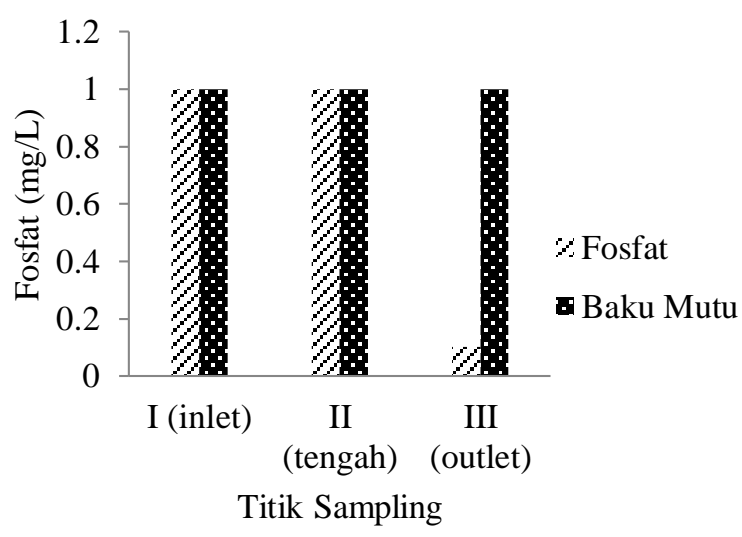

Gambar 9. Fosfat pada Embung Margodadi di tiap titik sampling

\section{Fecal Coliform}

Pada Gambar 10 nilai bakteri fecal coliform pada embung margodadi di tiap titik terlihat perbedaan yang signifikan. Pada titik I (inlet) bakteri fecal coliform berjumlah $44 \mathrm{MPN} / \mathrm{ml}$, titik II (tengah) yaitu $2400 \mathrm{MPN} / \mathrm{ml}$ dan titik III (outlet) $160 \mathrm{MPN} / \mathrm{ml}$. Jumlah bakteri fecal coliform yang melebihi baku mutu kualitas air kelas 3 yaitu pada titik II, karena nilai ambang batas baku mutunya adalah $2000 \mathrm{MPN} / \mathrm{ml}$. Tinggi rendahnya nilai bakteri fecal 
coliform ditentukan oleh kecepatan aliran air pada embung, hal ini terlihat pada jumlah nya yang semakin berkurang saat di titik III (outlet).

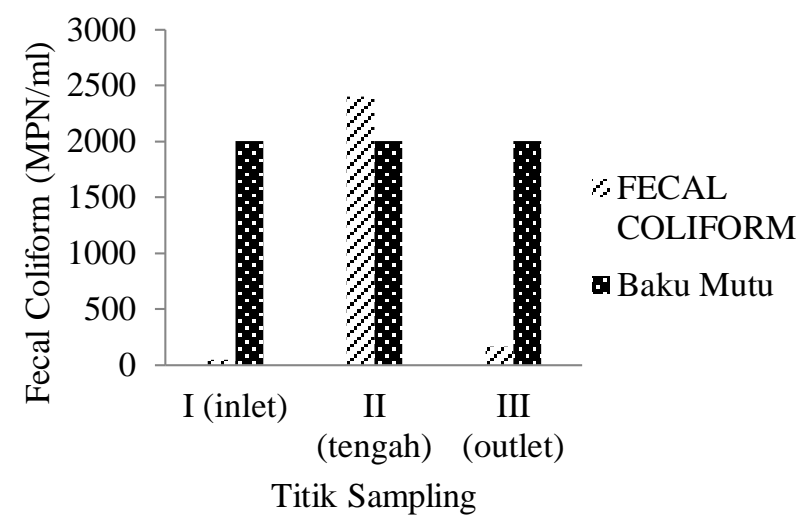

Gambar 10. Fecal Coliform pada Embung Margodadi di tiap titik sampling

Fecal coliform merupakan bakteri indikator polusi di perairan yang digunakan sebagai petunjuk adanya polusi feses atau kotoran manusia dan hewan. Dari hasil laboratorium terdapat bakteri E. Ccoli pada sampel air embung. E. coli adalah salah satu bakteri yang tergolong dalam fecal coliform, sebab bakteri tersebut dapat hidup secara baik dalam kotoran manusia ataupun hewan ${ }^{[6]}$.

\section{Indeks Kualitas Air}

Hasil analisis 9 parameter tersebut dengan memasukkan nilainya ke dalam indeks kualitas air, maka didapatkan hasil pada Gambar 11.

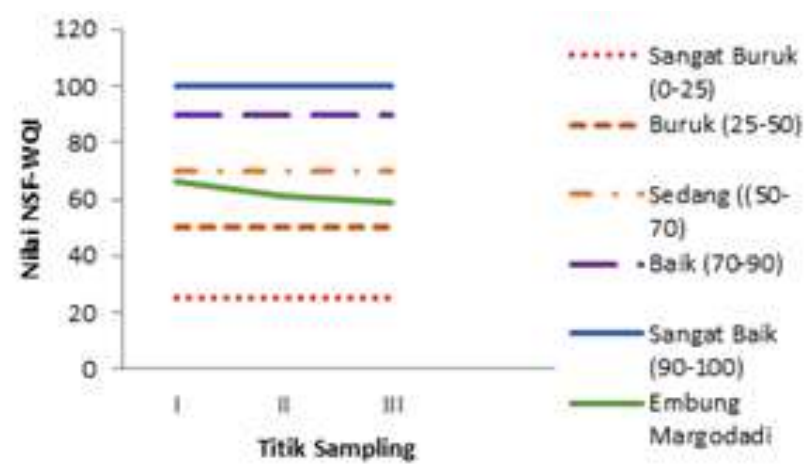

Gambar 11. Nilai Kualitas Air di tiap titik sampling dengan indeks NSF-WQI
Pada grafik tersebut menunjukkan indeks kualitas air di tiap titik sampling Embung Margodadi, yaitu antara 58,62 65,88 dengan status airnya sedang. Dari ketiga titik tersebut dapat ditarik hasil keseluruhan nilai kualitas air Embung Margodadi sedang memasuki tahapan pencemaran. Kualitas air dapat berubah jika nilai paremeter fiskokimia dan biologi tinggi yang disebabkan oleh beberapa faktor seperti kegiatan antropogenik dan pertanian disekitar embung.

\section{KESIMPULAN}

Berdasarkan hasil pengukuran parameter dan analisis dengan indeks kualitas air, air Embung Margodadi masih layak digunakan sebagai sumber air untuk irigasi.

\section{SARAN}

Masyarakat sekitar embung harus diberikan sosialisasi mengenai pentingnya menjaga lingkungan sekitar perairan, seperti mengurangi penggunaan pupuk kimia, mengurangi aktivitas membersihkan hewan peliharaan di embung, dan kegiatan antropogenik lainnya agar sumber air tidak tercemar.

\section{UCAPAN TERIMA KASIH}

Peneliti mengucapkan terimakasih kepada Kemenristekdikti yang membantu peneliti dalam pendanaan penelitian dosen pemula SIMLITABMAS.

\section{REFERENSI}

[1] Izzati, M., 2008, Perubahan Konsentrasi Oksigen Terlarut dan $\mathrm{pH}$ Perairan Tambak setelah Penambahan Rumput Laut Sargassum Plagyophyllum dan Ekstraknya, Tugas Akhir, Laboratorium Biologi Struktur dan Fungsi Tumbuhan Jurusan Biologi FMIPA, UNDIP, Semarang.

[2] Daphne, L. H. X., Utomo, H. D., Kenneth, L. Z. H., 2011, Correlation Between Turbidity and Total Suspended Solids in Singapore Rivers, Water Sustainability, 1(30), 313-322. 
[3] Kaban, S., Prianto, E., Solekha, 2010, Telaah Salinitas dan Oksigen Terlarut di Muara Sungai Pantai Timur Sumatera, Prosiding, Seminar Nasional Limnologi V, Palembang, Balai Riset Perikanan Perairan Umum.

[4] Davis, M.L., Cornwell, D. A., 1991, Introduction Environmental Engineering, Second Edition, MC-Graw-Hill, Inc.

[5] Barus, T. A., 2004, Pengantar Limnologi: Studi Tentang Ekosistem Air Daratan, USU Press.

[6] Fardiaz, S., 1992, Polusi Air dan Udara, Yogyakarta, Kanisius.

[7] Effendi, H., 2015, Simulasi Indeks Pencemaran dan Indeks Kualitas Air (NSF-WQI), Makalah, Puslitbang Kualitas dan Laboratorium Lingkungan, Kementerian Lingkungan Hidup dan Kehutanan, Jakarta

[8] Fahruddin, 2002, Pemanfaatan, ancaman, dan isu-isu pengelolaan ekosistem padang lamun. http://rudyct.tripod.com/sem2_012/fahru ddin.htm. [21 Agust 2004].

[9] Oram, B., 2014, Monitoring The Quality of Surface Waters (WQI Calculator). https://water-research.net/index.php/ water-treatment/water-monitoring/ monitoring-the-quality-of-surfacewaters. [1 Juli 2019].
[10] Van der Geer, J., Hanraads, J. A. J., Lupton, R. A., 2000, The Art of Writing A Scientific Article, Journal of Science Communication, 163, 51-59.

[11] Strunk, W., Jr., White, E. B., 1979, The Elements of Style (3rd ed.), New York, MacMillan.

[12] Mettam, G. R., Adams, L. B., 1999, How to Prepare An Alectronic Version of Your Aticle, In B. S. Jones \& R. Z. Smith (Eds.), Introduction to the electronic age (pp. 281-304). New York: E-Publishing Inc.

[13]Fachinger, J., den Exter, M., Grambow, B., Holgerson, S., Landesmann, C., Titov, M., 2004, Behavior of spent HTR fuel elements in aquatic phases of repository host rock formations, 2nd International Topical Meeting on High Temperature Reactor Technology, Beijing, China, paper \#B08.

[14]Fachinger, J., 2006, Behavior of HTR Fuel Elements in Aquatic Phases of Repository Host Rock Formations, Nuclear Engineering \& Design, 236, 54. 